\title{
Effectiveness of group versus individual hearing aid visits
}

\author{
Margaret P. Collins, PhD, CCC-A; ${ }^{1-3 *}$ Pamela E. Souza, PhD, CCC-A; ${ }^{3}$ Sami O’Neill, MA, CCC-A; ${ }^{2-3}$ \\ Bevan Yueh, MD, MPH ${ }^{1,4-6}$ \\ ${ }^{1}$ Health Services Research and Development Service and ${ }^{2}$ Rehabilitation Care Services, Department of Veterans \\ Affairs (VA) Puget Sound Health Care System, Seattle, WA; ${ }^{3}$ Department of Speech and Hearing Science, University of \\ Washington, Seattle, WA; ${ }^{4}$ Surgical and Perioperative Care Service, VA Puget Sound Health Care System, Seattle, WA; \\ Departments of ${ }^{5}$ Otolaryngology-Head and Neck Surgery and ${ }^{6}$ Health Services, University of Washington, Seattle, WA
}

\begin{abstract}
Demand for hearing aid services in the Veterans Health Administration increased over 300\% from 1996 to 2005, challenging the delivery of timely, high-quality care. Using group visits may help meet these needs, but whether this approach would still provide high-quality rehabilitation is unclear. This study determined whether group visits worsen hearing aid outcomes. It included a retrospective observational cohort in veterans seeking hearing aids at the Department of Veterans Affairs Puget Sound Health Care System from September 2004 to March 2005, when the clinic was using both individual and group visits. Medical records were reviewed for all new hearing aid patients seen during this period. Hearing-related outcome questionnaires were compared between patients seen for individual versus group fitting and/or follow-up visits. Results revealed that hearing thresholds were similar between patients seen individually and in groups. Of 74 patients who returned self-administered questionnaires after the follow-up, those who received both fitting and follow-up in a group format reported similar hearing handicap and better hearing-related function, satisfaction, and adherence than patients who received individual visits. Group visits did not appear to yield worse outcomes in this nonrandomized retrospective chart review. Definitive statements must await randomized comparisons.
\end{abstract}

Key words: education, group visits (non-Medical Subject Heading), health resources, health services research, hearing aids, hearing impaired, hearing loss, outcome assessment, patient satisfaction, rehabilitation of hearing impaired, veterans.

\section{INTRODUCTION}

Nearly 414,000 veterans had a service-related disability through the Department of Veterans Affairs (VA) for defective hearing in 2005, making hearing impairment the most common disability in veterans [1]. The Veterans' Health Care Eligibility Reform Act of 1996 (Public Law 104-262) and the Veterans Health Administration Directive 96-069 greatly expanded the number of veterans eligible for VA-issued hearing aids. More eligible veterans combined with the aging veteran population have increased the demand for hearing aid services in the VA by more than 300 percent from 1996 to 2005 [2].

\footnotetext{
Abbreviations: ACA $=$ Advanced Clinical Access, EAR = Effectiveness of Auditory Rehabilitation, G-G = group fitting and group follow-up, G-I = group fitting and individual followup, HHIE = Hearing Handicap Inventory for the Elderly, HLAA = Hearing Loss Association of America, I-G = individual fitting and group follow-up, I-I = individual fitting and individual follow-up, PSHCS = Puget Sound Health Care System, QOL = quality of life, SADL = Satisfaction with Amplification in Daily Life, SC = service and cost, SD = standard deviation, VA = Department of Veterans Affairs.

*Address all correspondence to Margaret P. Collins, PhD, CCC-A; Rehabilitation Care Services, Audiology Clinic, 126, VA Puget Sound Health Care System, 1600 South Columbian Way, Seattle, WA 98108; 206-764-2404; fax: 206-764-2672. Email: margaret.collins@va.gov

DOI: 10.1682/JRRD.2007.02.0029
} 
Implementing approaches that provide more efficient treatment without compromising quality of care has become a focus of the VA through a program called “Advanced Clinical Access" (ACA) [3]. One of the components of ACA is to increase clinical capacity by offering group visits that allow more patients to be seen with the same amount of resources as traditional one-on-one encounters. Audiological rehabilitation visits aimed at teaching new hearing aid wearers how to use their hearing aids effectively may be appropriate for a group format because they contain standardized information and common discussion themes that are relevant to all new patients. However, before they could be recommended for routine care, showing that group visits do not lead to worse outcomes would be critical.

National organizations such as the Hearing Loss Association of America (HLAA) recognize the potential value of group visits [4]. The HLAA recommends that all hearing aid wearers have the opportunity to participate in group hearing aid orientation classes because of the potential benefits from shared information and support with other hearing aid wearers. A number of VA audiology programs have started offering group hearing aid fitting and/or follow-up appointments. While a number of studies suggest that group aural rehabilitation visits can produce equivalent or better patient outcomes when offered as a supplement to standard care [5-19], only limited observational evidence suggests that group follow-up visits yield hearing aid patient outcomes (e.g., hearing handicap, satisfaction, adherence) that are at least as good as individual visits [20]. No studies have been published that compare group and individual hearing aid fitting visits.

If evidence indicates that group hearing aid visits do not worsen outcomes, then group visits might reduce the strain on VA resources and waiting times while maintaining care for more veterans. This investigation gained more insight into whether group hearing aid fitting and follow-up visits yielded patient outcomes similar to or better than individual visits. We hypothesized that group visits would yield equivalent or improved patient outcomes when compared with individual visits.

\section{METHODS}

We conducted a retrospective chart review to compare hearing aid outcomes for new hearing aid patients who received group hearing aid fitting and follow-up visits with those who received individual fitting and follow-up visits at the VA Puget Sound Health Care System (VAPSHCS) between September 2004 and March 2005. We chose this time frame because group visits were being offered concurrently with individual visits, which permitted comparisons with a concurrent control group. The University of Washington Institutional Review Board and the Research and Development Review Committee at the VAPSHCS approved all procedures.

Before the introduction of digital technology at the VAPSHCS, group hearing aid visits were routinely offered. Group visits were discontinued during the transition to digitally programmable technology in the late 1990s because of the increased complexity of hearing aid programming and varying wearer options (e.g., multimemories with or without memory button, directional microphone, remote control, and switchless telecoil). As audiologists learned the technology, fitting practices became more standardized, but wearer options varied more between patients than with former conventional circuits. To relieve increasing appointment backlogs and some of the strain on clinic resources, VAPSHCS explored the viability of again using a group format with the added challenges of digital hearing aid fittings.

The VA Puget Sound Audiology Clinic fitted hearing aids for most new hearing aid wearers with a series of three visits that included an evaluation, fitting, and follow-up. A patient was considered a new wearer if he or she had no hearing aid use during the last year. Candidacy for amplification was determined at the evaluation. If indicated, hearing aids were ordered and fitted approximately 4 weeks later at the hearing aid fitting. The patient was seen for a follow-up visit approximately 4 weeks after the fitting. Starting in September 2004, one 4-person group fitting and one 4-person group follow-up were offered each week. After these group appointments were filled, appointments were scheduled individually (we encouraged the patient's significant other to attend all appointments). Therefore, patients could have received their fitting and follow-up appointments in any one of the following four combinations (Table 1):

1. Individual fitting and individual follow-up (I-I).

2. Individual fitting and group follow-up (I-G).

3. Group fitting and individual follow-up (G-I).

4. Group fitting and group follow-up (G-G).

\section{Hearing Aid Fitting Appointments}

All hearing aid fittings consisted of two segments: programming and orientation. First, all patients received a 30-minute individual hearing aid programming session 
Table 1.

Hearing aid fitting and follow-up visits of individual and group combinations.

\begin{tabular}{|c|c|c|}
\hline \multirow{2}{*}{$\begin{array}{l}\text { Follow-Up } \\
\text { Individual } \\
\text { Group }\end{array}$} & \multicolumn{2}{|c|}{ Fitting } \\
\hline & $\begin{array}{l}\text { Individual } \\
\text { I-I } \\
\text { I-G }\end{array}$ & $\begin{array}{l}\text { Group } \\
\text { G-I } \\
\text { G-G }\end{array}$ \\
\hline \multicolumn{3}{|c|}{$\begin{array}{l}\text { G-G = group fitting and group follow-up, G-I = group fitting and } \\
\text { individual follow-up, I-G = individual fitting and group follow-up, } \\
\text { I-I = individual fitting and individual follow-up. }\end{array}$} \\
\hline
\end{tabular}

with an audiologist. At this time, the hearing aids were adjusted for the patient's specific requirements. The use of hearing aid controls, such as a volume control, memory button, directional microphone, switchless telecoil, and remote control, was explained during programming. Second, after the individual programming session, patients received either a group or an individual orientation.

For the group orientation, four patients and their significant others, if attending, convened for 60 minutes in a quiet conference room in the audiology clinic, for a total visit time of 90 minutes. One of the staff audiologists conducted the orientation. Teaching topics included how a hearing aid works; use, care, and maintenance; acoustic feedback; battery use, replacement, and ordering; telephone use; warrantee and repairs; listening and communication skills; and realistic expectations. A PowerPoint (Microsoft Corp, Redmond, Washington) slide show combined with hands-on practice facilitated the teaching.

The same audiologist who performed the patient's 30-minute programming also conducted the individual orientations typically lasting 30 minutes, for a total visit time of 60 minutes. Both programming and orientation occurred in the same quiet conference room. Teaching topics were the same as for those in the group orientation but without the PowerPoint slide show.

\section{Hearing Aid Follow-Up Appointments}

Group follow-up visits lasted 60 minutes and consisted of a 30-minute topic discussion, including a review of information covered in the fitting, effects of acquired hearing loss, coping with hearing loss, communication strategies for the hearing aid wearers and their significant others, and realistic expectations. The group also watched a 15-minute video addressing how to benefit the most from new hearing aids [21]. This session was conducted by a staff audiologist in a quiet conference room in the audiology clinic and facilitated by a PowerPoint slide show. The remaining 15 minutes were used for adjusting hearing aids for individual patients as needed.

An individual follow-up consisted of a 30-minute visit with an audiologist to discuss problems and to adjust hearing aid when appropriate. The same topics were discussed as in the group sessions but tailored to the specific needs and concerns of the individual patient.

\section{Inclusion and Exclusion Criteria}

We reviewed the charts of all patients considered new hearing aid wearers (i.e., no hearing aid use during the last year) from September 2004 to March 2005. We excluded patients from the analyses if they were fitted with anything other than monaural or binaural air conduction hearing aids (e.g., contralateral and binaural contralateral routingof-signal configurations and bone-anchored aids were excluded), did not complete both the fitting and follow-up appointments, or did not return at least one of the questionnaires within 90 days of the follow-up appointment.

\section{Outcome Measures}

Although prior experience with group hearing aid visits using conventional hearing aid circuitry had been successful, the effectiveness of groups with programmable digital hearing aids was unknown, given the added complexity and additional wearer options often provided. To evaluate the effectiveness of these group visits using various outcome measures, the clinic mailed the following questionnaires to hearing aid wearers who were fitted with hearing aids between September 2004 and March 2005 and who also returned for their 1-month follow-up appointment:

- Hearing Handicap Inventory for the Elderly (HHIE) [22-23]. The HHIE is a 25-item questionnaire that measures social and emotional hearing-related disability. The scale is scored from 0 to 100 , with higher scores indicating more handicap.

- Effectiveness of Auditory Rehabilitation (EAR) [24]. The EAR is a two-module scale that was developed to assess important issues for hearing aid patients. The first module or "Inner EAR" has 10 items that address intrinsic hearing issues such as ability to hear in quiet and in noise as well as emotional and social effects of hearing loss. It is scored from 0 to 100 , with higher scores indicating better function. The second module or "Outer EAR" also has 10 items and covers extrinsic hearing aid-related issues such as comfort, convenience, and cosmetics of hearing aid use. Like the Inner EAR, it is scored from 0 to 100, 
with higher scores indicating better function. The Inner EAR can be administered to all patients, while the Outer EAR applies only to patients who have received hearing aids. Both modules have excellent reliability and validity and are highly sensitive to clinical change [24]. Veterans at VAPSHCS who are hearing-impaired and awaiting hearing aids typically have scores ranging from 25 to 30 and successful hearing aid wearers score from 55 to 60 .

- Satisfaction with Amplification in Daily Life (SADL) [25-26]. The SADL is a 14-item scale that measures satisfaction with hearing aids (item 15 on cost was omitted because VA patients did not pay for their hearing aids). It provides a global score indicating overall satisfaction and the following four subscales: (1) "positive effects" capture perceived improvement in performance and function, (2) satisfaction with "service and cost" (SC), (3) "negative features" that address annoying aspects of hearing aid use such as feedback and background noise, and (4) "personal image" that covers aspects of self-image and hearing aid stigma [25]. Scores range from 1 to 7, with higher scores indicating more satisfaction. Construct and internal validity of the SADL are strong [26].

- Hours of Use. Patients also were asked how many hours a day they used their hearing aids. The HHIE and Inner EAR were given to patients receiving hearing aid evaluations and reflected baseline hearingrelated function.

\footnotetext{
*Yueh B, Collins MP, Souza PE, Boyko E, Loovis CF, Heagerty P, Liu CF, Hedrick SC. Long-term effectiveness of screening for hearing loss: The screening for auditory impairment-Which hearing assessment test (SAI-WHAT) randomized trial. Unpublished observations; 2007.
}

The HHIE, Inner EAR, Outer EAR, SADL, and Hours of Use questions were mailed 2 weeks after the follow-up appointment (third appointment of three) to all patients.

\section{Statistical Analyses}

We used standard bivariate techniques to compare groups, including Fisher's exact tests for proportional data and $t$-tests for continuous data. The level of statistical significance was $p \leq 0.05$. To measure change in hearing-related function (HHIE and Inner EAR), we compared differences between baseline and follow-up scores. For the HHIE, a negative number indicated hearing handicap improved (i.e., less handicap). For the Inner EAR, a positive number indicated hearing-related function improved (i.e., better function). Analysis of variance was used when three or more groups were compared.

\section{RESULTS}

From September 2004 to March 2005, 107 new hearing aid patients who had both fitting and follow-up visits were asked to complete questionnaires. Of these patients, 77 completed and returned at least one of the questionnaires and 74 did so within 90 days (69\% response rate). Of these 74 patients, 15 had I-I, 12 had G-I, 10 had I-G, and 37 had G-G combination visits. Demographic, hearing threshold, and hearing aid data for these 74 patients are shown in Table 2. We found no statistically significant differences between the categories of patients by sex, age, hearing thresholds, prior hearing aid use, or monaural use. One ear of one patient had a mixed hearing loss. All other losses were sensorineural. Most patients were fitted binaurally and had no prior hearing aid

Table 2.

Demographic, hearing threshold, and hearing aid data for hearing aid patients in four appointment groups (individual and group combinations).

\begin{tabular}{|c|c|c|c|c|c|}
\hline Characteristic & $\begin{array}{c}\text { I-I } \\
(n=15)\end{array}$ & $\begin{array}{c}\text { G-I } \\
(n=12)\end{array}$ & $\begin{array}{c}\text { I-G } \\
(n=10)\end{array}$ & $\begin{array}{c}\text { G-G } \\
(n=37)\end{array}$ & $p$-Value \\
\hline Male (\%) & 93.3 & 100.0 & 100.0 & 100.0 & 0.99 \\
\hline Age, yr (mean \pm SD) & $65.9 \pm 11.9$ & $67.9 \pm 8.8$ & $66.8 \pm 8.9$ & $67.3 \pm 9.7$ & 0.96 \\
\hline Right-Ear HF PTA (dB HL \pm SD) & $52.1 \pm 17.4$ & $51.5 \pm 14.2$ & $49.6 \pm 11.5$ & $48.6 \pm 14.2$ & 0.86 \\
\hline Left-Ear HF PTA (dB HL \pm SD) & $54.9 \pm 12.6$ & $59.9 \pm 8.8$ & $54.5 \pm 15.4$ & $53.9 \pm 13.0$ & 0.57 \\
\hline Prior Hearing Aid Use (\%) & 13.3 & 25.0 & 20.0 & 18.9 & 0.92 \\
\hline Monaural Hearing Aid Use (\%) & 13.3 & 25.0 & 0.0 & 21.6 & 0.61 \\
\hline
\end{tabular}

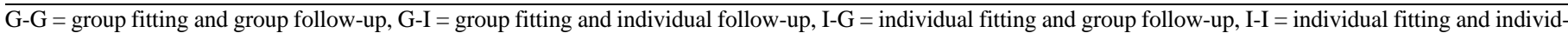
ual follow-up, HF PTA = high-frequency pure-tone average (average of thresholds at 1,000, 2,000, 3,000, and 4,000 Hz), HL = hearing level, SD = standard deviation. 
experience. All patients were fitted with programmable hearing aids, and all but one hearing aid was digital. The four in-the-ear hearing aid styles (full-shell, half-shell, canal, completely in-the-canal) were fitted with similar frequencies across the four group combinations. Behindthe-ear aids were fitted more frequently in the G-I group than the other groups.

\section{Individual Fitting and Follow-Up Versus Group Fitting and Follow-Up}

Our primary interest for this investigation was to evaluate differences in outcomes between group and individual visits; therefore, we first compared outcomes between patients who received I-I visits with those who received G-G visits, where the most robust effects of appointment type were expected. The mean \pm standard deviation (SD) results of the five outcomes for these appointment combinations are shown in Table 3. In all five outcome measures, the G-G patients scored better. The magnitude of the improvement with the HHIE questionnaire was substantial (22.0 vs 35.4 points), although insufficient power existed to demonstrate statistical significance. Inner EAR scores showed that hearing-related function improved 12.5 points more for the G-G patients than for the I-I patients $(p<0.05)$. Both the Outer EAR and global SADL scores suggested better hearing-aid function in the G-G patients $(p<0.05$ with both mea-

\section{Table 3.}

Mean \pm standard deviation results for hearing outcomes measures for all subjects in individual fitting and individual follow-up (I-I) and group fitting and group follow-up (G-G) appointment groups. Number of subjects shown in parentheses.

\begin{tabular}{cccc}
\hline $\begin{array}{c}\text { Outcome } \\
\text { Measure }\end{array}$ & I-I & G-G & p-Value \\
\hline $\begin{array}{c}\text { HHIE } \\
\text { (change) }\end{array}$ & $\begin{array}{c}-22.0 \pm 25.9 \\
(11)\end{array}$ & $\begin{array}{c}-35.4 \pm 23.6 \\
(28)\end{array}$ & 0.13 \\
Inner EAR & $31.8 \pm 22.3$ & $44.3 \pm 18.4$ & 0.04 \\
(change) & $(15)$ & $(37)$ & \\
Outer EAR & $63.9 \pm 18.4$ & $75.1 \pm 14.8$ & 0.03 \\
(change) & $(15)$ & $(36)$ & \\
SADL Global & $5.2 \pm 1.0$ & $5.8 \pm 0.6$ & 0.03 \\
& $(15)$ & $(37)$ & \\
Hours of Use & $10.2 \pm 3.3$ & $12.4 \pm 2.8$ & 0.02 \\
& $(14)$ & $(37)$ & \\
\hline
\end{tabular}

Note: Change in hearing-related function was measured based on comparing differences between baseline and follow-up scores.

EAR = Effectiveness of Auditory Rehabilitation, HHIE = Hearing Handicap Inventory for the Elderly, SADL = Satisfaction with Amplification in Daily Life. sures). The direction of the difference in the SADL was reflected in all four SADL subscales, but only the SC subscale reached statistical significance $(p=0.05)$ (Table 4). Finally, G-G patients reported wearing their hearing aids an average of 2.2 hours longer each day than I-I patients, which was statistically significant as well.

Because the I-I versus G-G comparison was not randomized, it is subject to treatment bias. Even though patients were distributed equally between groups, we considered that in a clinical setting, allocation to individual versus group assignments could have been influenced by prior hearing aid use and monaural versus binaural fittings. We therefore pursued stratified analyses by these two potential confounding variables.

\section{Prior Hearing Aid Use}

To examine whether prior hearing aid experiences affected the benefit received from rehabilitation, we stratified our analyses by prior hearing aid use and no prior hearing aid use. For the 43 patients who had no prior hearing aid use, mean \pm SD scores are shown in the second and third columns of Table 5 and were similar to those for the unstratified analyses shown in Table 3, with the G-G patients scoring better on all five outcome measures. Again, the differences were statistically significant for the Inner $\operatorname{EAR}(p=0.04)$, Outer $\operatorname{EAR}(p=0.05)$, SADL $(p=$ $0.01)$, and Hours of Use $(p=0.03)$. Only nine patients who had previously worn hearing aids received I-I visits, providing limited statistical power. Scores are shown in the fifth and sixth columns of Table 5. The direction of the differences was toward better outcomes for G-G patients for the HHIE, Inner and Outer EAR, and Hours of Use, but worse with for SADL.

Table 4.

Mean \pm standard deviation results for Satisfaction with Amplification in Daily Life (SADL) subscales for all subjects in individual fitting and individual follow-up (I-I) and group fitting and group follow-up (G-G) appointment groups. Number of subjects shown in parentheses.

\begin{tabular}{lccc}
\hline $\begin{array}{c}\text { Outcome } \\
\text { Measure (SADL) }\end{array}$ & I-I & G-G & $\boldsymbol{p}$-Value \\
\hline Positive Effects & $4.9 \pm 1.4$ & $5.7 \pm 0.8$ & 0.08 \\
& $(15)$ & $(37)$ & \\
Service and Cost & $6.0 \pm 0.9$ & $6.5 \pm 0.7$ & 0.05 \\
& $(14)$ & $(37)$ & \\
Negative Features & $5.0 \pm 1.6$ & $5.4 \pm 1.0$ & 0.25 \\
& $(15)$ & $(37)$ & \\
Personal Image & $5.4 \pm 1.2$ & $6.1 \pm 0.9$ & 0.10 \\
& $(14)$ & $(37)$ & \\
\hline \hline
\end{tabular}




\section{Binaural Versus Monaural Aids}

Similarly, monaural wearers may have used different communication strategies and/or relied on their hearing aids in different ways from binaural wearers that may have affected the effectiveness of group visits. In stratified analyses, mean \pm SD scores for the 41 patients who were binaural wearers are shown in the second and third columns of Table 6. The magnitude and direction of the differences were similar to those for the unstratified analyses shown in Table $\mathbf{3}$ and approached, but did not reach, statistical significance for the Inner $\operatorname{EAR}(p=0.06)$, Outer EAR $(p=0.06)$, and SADL $(p=0.09)$. For the 11 monaural wearers, only 2 were in the I-I combination, yielding little statistical power, but the direction of the differences favored the G-G combination for all five outcomes and was statistically significant for the number of hours used each day, in which G-G wearers wore their hearing aids an average of 5.2 hours longer than I-I group wearers $(p=0.002)$. These scores are shown in the fifth and sixth columns of Table 6.

Table 5.

Mean \pm standard deviation results for hearing outcome measures for subjects in individual fitting and individual follow-up (I-I) and group fitting and group follow-up (G-G) appointment groups by hearing aid experience. Number of subjects shown in parentheses.

\begin{tabular}{|c|c|c|c|c|c|c|}
\hline \multirow{2}{*}{$\begin{array}{l}\text { Outcome } \\
\text { Measure }\end{array}$} & \multicolumn{3}{|c|}{ No Prior Hearing Aid Use } & \multicolumn{3}{|c|}{ Prior Hearing Aid Use } \\
\hline & I-I & G-G & $p$-Value & I-I & G-G & $p$-Value \\
\hline HHIE (change) & $\begin{array}{c}-20.9 \pm 23.7 \\
(9)\end{array}$ & $\begin{array}{c}-35.0 \pm 22.1 \\
(22)\end{array}$ & 0.13 & $\begin{array}{c}-27.0 \pm 46.7 \\
(2)\end{array}$ & $\begin{array}{c}-36.6 \pm 30.6 \\
(6)\end{array}$ & 0.74 \\
\hline Inner EAR (change) & $\begin{array}{c}33.2 \pm 19.6 \\
(13)\end{array}$ & $\begin{array}{c}44.9 \pm 15.9 \\
(30)\end{array}$ & 0.04 & $\begin{array}{c}23.1 \pm 46.4 \\
\text { (2) }\end{array}$ & $\begin{array}{c}41.8 \pm 28.5 \\
(7)\end{array}$ & 0.49 \\
\hline SADL Global & $\begin{array}{l}5.1 \pm 1.0 \\
\quad(13)\end{array}$ & $\begin{array}{c}5.9 \pm 0.6 \\
(30)\end{array}$ & 0.01 & $\begin{array}{c}5.7 \pm 1.3 \\
(2)\end{array}$ & $\begin{array}{c}5.4 \pm 0.6 \\
\quad(7)\end{array}$ & 0.52 \\
\hline Hours of Use & $\begin{array}{c}10.2 \pm 3.6 \\
(12)\end{array}$ & $\begin{array}{c}12.5 \pm 2.8 \\
(30)\end{array}$ & 0.03 & $\begin{array}{c}10.5 \pm 0.7 \\
(2)\end{array}$ & $\begin{array}{c}11.7 \pm 2.8 \\
(7)\end{array}$ & 0.57 \\
\hline
\end{tabular}

Table 6.

Mean \pm standard deviation results for hearing outcome measures for subjects in individual fitting and individual follow-up (I-I) and group fitting and group follow-up (G-G) appointment groups by binaural and monaural hearing aid use. Number of subjects shown in parentheses.

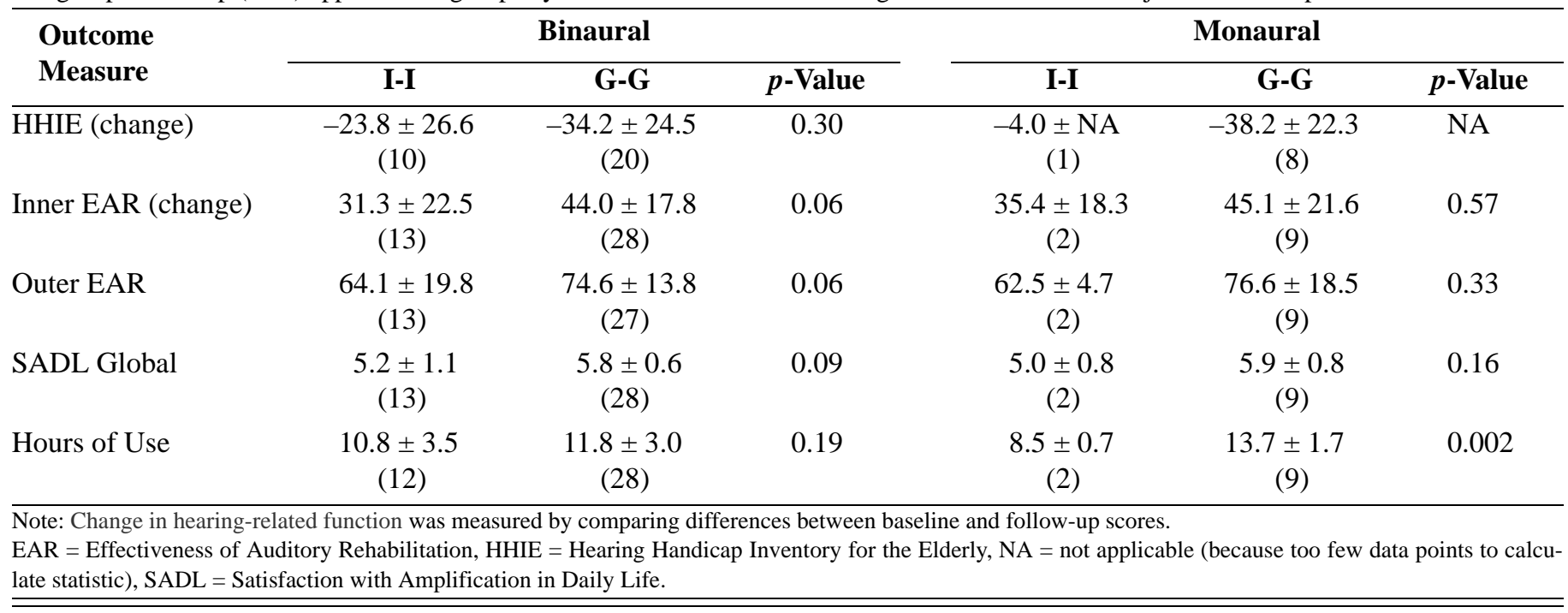




\section{Fitting Versus Follow-up}

To determine whether the fitting or follow-up visit had greater influence on the improved outcomes, we compared the effect of the type of hearing aid fitting, regardless of the type of follow-up visit (i.e., the I-G and I-I patients were grouped together, and the G-G and G-I patients were grouped together). We chose this bivariate method of analysis to increase statistical power over a four-group comparison. Results in mean \pm SD for each of the five outcome measures categorized by type of hearing aid fitting are shown in Table 7. The second column (I-I and I-G) shows the results for all patients who received individual fittings, and the third column (G-I and G-G) shows the results for all patients who received group fittings. The direction of the differences indicated that outcomes were better when the fitting was provided in a group format. These differences were statistically significant for the Outer EAR and approached significance for the Inner EAR, SADL, and Hours of Use.

Similarly, we examined the effect of group versus individual follow-up appointments, regardless of the type of fitting visit. Results in mean \pm SD for each of the five

Table 7.

Mean \pm standard deviations for hearing outcome measures for all hearing aid patients based on comparisons of individual (I) fitting vs group (G) fitting visits. Number of subjects shown in parentheses.

\begin{tabular}{|c|c|c|c|}
\hline $\begin{array}{l}\text { Outcome } \\
\text { Measure }\end{array}$ & $\begin{array}{c}I^{*} \\
\text { (I-I and I-G) }\end{array}$ & $\begin{array}{c}\mathrm{G}^{*} \\
\text { (G-I and G-G) }\end{array}$ & $p$-Value \\
\hline $\begin{array}{l}\text { HHIE } \\
\text { (change) }\end{array}$ & $\begin{array}{c}-30.9 \pm 26.6 \\
(21)\end{array}$ & $\begin{array}{c}-34.8 \pm 27.0 \\
(38)\end{array}$ & 0.59 \\
\hline $\begin{array}{r}\text { Inner EAR } \\
\text { (change) }\end{array}$ & $\begin{array}{c}35.6 \pm 23.3 \\
(24)\end{array}$ & $\begin{array}{c}43.8 \pm 17.8 \\
(49)\end{array}$ & 0.10 \\
\hline Outer EAR & $\begin{array}{c}67.9 \pm 16.5 \\
(25)\end{array}$ & $\begin{array}{c}75.2 \pm 14.4 \\
(48)\end{array}$ & 0.05 \\
\hline SADL Global & $\begin{array}{l}5.4 \pm 0.9 \\
\quad(25)\end{array}$ & $\begin{array}{l}5.8 \pm 0.6 \\
(49)\end{array}$ & 0.06 \\
\hline Hours of Use & $\begin{array}{c}10.7 \pm 2.8 \\
\quad(24)\end{array}$ & $\begin{array}{c}11.9 \pm 3.0 \\
(49)\end{array}$ & 0.11 \\
\hline \multicolumn{4}{|c|}{$\begin{array}{l}\text { Note: Change in hearing-related function was measured by comparing differ- } \\
\text { ences between baseline and follow-up scores. } \\
\text { *'Patients who received individual fittings with I-I and I-G patients were } \\
\text { grouped together, and patients who received group fittings with G-I or G-G } \\
\text { patients were grouped together. } \\
\text { EAR = Effectiveness of Auditory Rehabilitation, G-G = group fitting and group } \\
\text { follow-up, G-I = group fitting and individual follow-up, HHIE = Hearing Hand- } \\
\text { cap Inventory for the Elderly, I-G = individual fitting and group follow-up, I-I = } \\
\text { individual fitting and individual follow-up, SADL = Satisfaction with Amplifica-a } \\
\text { tion in Daily Life. }\end{array}$} \\
\hline
\end{tabular}

outcomes categorized by type of hearing aid follow-up appointment are shown in Table 8. The second column (I-I and G-I) shows the results for all patients who received individual follow-ups, and the third column (I-G and $\mathrm{G}-\mathrm{G}$ ) shows the results for all patients who received group follow-ups. As with the fitting appointment comparisons, the direction of the differences indicated that outcomes were better when the follow-up appointment was provided in a group format. The sample sizes were again small but were still statistically significant for the Hours of Use and approached significance for the Inner and Outer EAR and SADL.

\section{DISCUSSION}

In this nonrandomized retrospective chart review of new hearing aid patients seen between September 2004 and March 2005 at the VAPSHCS, we found that those who received their hearing aid fitting and follow-up visits

Table 8.

Mean \pm standard deviations for hearing outcome measures for all hearing aid patients based on comparisons of individual (I) follow-up vs group (G) follow-up visits. Number of subjects shown in parentheses.

\begin{tabular}{|c|c|c|c|}
\hline $\begin{array}{l}\text { Outcome } \\
\text { Measure }\end{array}$ & $\begin{array}{c}\mathbf{I}^{*} \\
\text { (I-I and G-I) }\end{array}$ & $\begin{array}{c}\mathrm{G}^{*} \\
\text { (I-G and G-G) }\end{array}$ & $p$-Value \\
\hline $\begin{array}{l}\text { HHIE } \\
\text { (change) }\end{array}$ & $\begin{array}{c}-27.4 \pm 31.2 \\
(21)\end{array}$ & $\begin{array}{c}-36.7 \pm 23.7 \\
(38)\end{array}$ & 0.20 \\
\hline $\begin{array}{r}\text { Inner EAR } \\
\text { (change) }\end{array}$ & $\begin{array}{l}36.4 \pm 20.1 \\
\quad(27)\end{array}$ & $\begin{array}{c}43.8 \pm 19.6 \\
\quad(46)\end{array}$ & 0.13 \\
\hline Outer EAR & $\begin{array}{c}69.0 \pm 17.2 \\
(27)\end{array}$ & $\begin{array}{c}74.8 \pm 14.1 \\
\quad(46)\end{array}$ & 0.12 \\
\hline SADL Global & $\begin{array}{l}5.4 \pm 0.9 \\
(27)\end{array}$ & $\begin{array}{l}5.8 \pm 0.6 \\
(47)\end{array}$ & 0.06 \\
\hline Hours of Use & $\begin{array}{c}10.3 \pm 3.3 \\
\quad(26)\end{array}$ & $\begin{array}{c}12.1 \pm 2.6 \\
(47)\end{array}$ & 0.01 \\
\hline
\end{tabular}

Note: Change in hearing-related function was measured by comparing differences between baseline and follow-up scores.

*Patients who received individual follow-ups with I-I and G-I patients were grouped together, and patients who received group follow-ups with I-G and G-G patients were grouped together.

EAR = Effectiveness of Auditory Rehabilitation, $\mathrm{G}-\mathrm{G}=$ group fitting and group follow-up, G-I = group fitting and individual follow-up, HHIE $=$ Hearing Handicap Inventory for the Elderly, I-G = individual fitting and group follow-up, I-I = individual fitting and individual follow-up, SADL = Satisfaction with Amplification in Daily Life. 
in a group format had hearing aid outcomes as good as or better than patients who received these appointments in an individual format. We found no statistical difference in the reduction of hearing handicap between the groups, but found better outcomes for hearing-related function, hearing aid-related function, satisfaction, and hours used each day for patients who received group visits. These data suggest that patients are not harmed by group visits (noninferior). However, the observational (nonrandomized) nature of the study design (and the predominance of older male veteran patients, all of whom received their hearing aids free of charge), limits our ability to attribute superiority to the group visits and to generalize results to nonveteran patients. These data should be interpreted cautiously until more evidence from randomized designs sufficiently powered to detect statistically and clinically significant differences is available.

These results are not surprising in light of findings from a number of large managed care organizations using group appointments for chronic disease management. They have found not only lower costs [27-29] and reduced utilization [27,29-31] but also improved patient satisfaction [27,31-33], self-efficacy [29,31], health status, [28,31,33-38], compliance [39], and quality of life (QOL) [29]. For example, in a randomized trial comparing group versus individual outpatient visits for patients with a variety of chronic illnesses, patients treated in group appointments had fewer emergency room and subspecialty visits, fewer hospital admissions, greater patient and provider satisfaction, and lower overall costs [27]. Patients who received group visits reported that their health care needs were better met and that overall access to care was improved. Physicians also reported higher satisfaction with group than individual care that may have been related to the efficiency of the group sessions that allowed more time for discussing critical issues with patients, resulting in better-informed patients without repetition. A similar randomized trial found that 40.0 percent of patients randomized to group visits in a chronic care clinic rated their care as excellent after 1 year of follow-up versus 25.3 percent of patients receiving usual care through individual physician visits [32]. Scott et al. recently demonstrated in a randomized trial of outpatient visits for chronically ill older health maintenance organization patients, group participants had lower utilization, higher satisfaction, and better QOL and self-efficacy, with significant cost savings [29].
Data from randomized trials represent the highest level of evidence about the value of interventions [40]. To our knowledge, no randomized trials have compared group versus individual visits; however, two other nonrandomized studies of follow-up appointments support our findings. Brickley, Cleaver, and Bailer conducted a retrospective observational study of the effectiveness of group versus individual hearing aid follow-up visits [20]. They compared outcomes for 49 patients who received a group visit with 49 patients who received an individual visit and were matched for age, sex, and hearing loss. They found no differences between group and individual visits for hours of hearing aid use or satisfaction; however, the group sessions were less expensive to conduct and the patients reported better performance and returned for fewer unplanned follow-up appointments. Nonattendance was higher for the group sessions, and the study was at risk for confounding since they did not randomize treatments. Taylor examined the effect of group composition on an 8- to 10-hour aural rehabilitation program [41]. Sixty patients received training in one of three formats: (1) individually, (2) in a group of 10 patients each accompanied by their spouse, or (3) in a group of 10 patients each accompanied by a friend. Patients who participated in the group sessions reported less hearing handicap and more satisfaction with their audiologist than those who participated individually.

A number of factors may influence how patients respond to group visits. Veterans receive hearing aids free of charge, so their motivation to participate in group visits may be different from nonveteran patients. Patients who wear an aid monaurally may have different rehabilitation needs than those who wear an aid binaurally and, therefore, may receive different benefits from group visits. For example, if a patient does not wear an aid on one ear because that ear is normal, that patient may rely more on environmental modification rather than communication strategies than a patient who is a bilateral hearing aid wearer, thus requiring different training. Prior experience with hearing aids may also affect how patients respond to a group visit. For example, a patient who knows how to change the batteries or clean the aid may not want detailed information or to listen to others' questions about this topic and, in turn, may be less satisfied with the group experience than someone with no prior experience. Our stratification by number of ears aided and by prior hearing aid use showed no clear effects. Because this was a retrospective review of patients who completed outcome questionnaires for a quality-improvement activity, the number 
of patients in these subgroups was small, limiting our ability to achieve insights into these and other potential mediating factors.

The outcomes in this investigation were measured after both the fitting and follow-up visits and showed the combined effects of the fitting and follow-up. To gain insight into which, if either, appointment was more important to the outcomes, we looked at the effects of the type of fitting regardless of the type of follow-up (i.e., all patients who received an individual fitting compared with all patients who received a group fitting) and of the type of follow-up regardless of the type of fitting (i.e., all patients who received an individual follow-up compared with all patients who received a group follow-up). No clear pattern emerged: outcomes scores were essentially the same either way. Additional research is needed to better understand which appointments are (or whether both are) more effective in a group format.

Although no data definitively support the precise mechanisms of group visits that produce better outcomes, several mediators have been postulated, including presence of family members [42-44], more attention from providers [45-47], group interactions that foster camaraderie [19,38,42-44,47-48] and reduce social isolation $[19,27,42,49]$, and shared insights and experiences $[27,43-44,47,49]$. In addition, a more relaxed pace and repetition $[34,38-39,49]$ and more opportunities for questions $[19,39,47]$ may help patients retain information. However, researchers also have raised questions about loss of privacy [45] and social discomfort [29]. We need to understand which of these elements are important to the group process so that the most effective group formats can be offered. Future studies should address these and other features. Hawkins' review of the effectiveness of group aural rehabilitation programs concluded that large randomized controlled trials are needed that include patients from the general population (i.e., nonveterans), use multiple measures that assess various outcome domains (e.g., handicap, benefit, satisfaction, QOL), study the effects of participation by significant others, and measure effects at short- and long-term intervals [12].

Long-term cost saving with group appointments is also important to consider when determining the effectiveness of group appointments to reduce the strain on scarce resources. Immediate cost savings can be realized with the reduced audiology hours required for group hearing aid fitting and follow-up visits. However, the impact on longer-term costs over the rehabilitation period is less clear. For example, if group treatment is effective, the higher level of learning and information retention may leads to long-term savings from fewer subsequent unplanned visits and hearing aid repairs. On the other hand, if group sessions are less effective and patients do not learn how to use their aids optimally, the result may be more unplanned visits and more hearing aid repairs.

To address some of the many questions about the effectiveness of group visits, the VA Health Services Research and Development Service has funded a 3-year randomized controlled trial called "Hearing Aid Effectiveness After Aural Rehabilitation: Individual Versus Group.”*

This trial is designed to determine if group visits are at least as effective as individual visits for hearing aid fitting and follow-up. The primary outcomes will be hearing-related function using the Inner EAR and hearing aid adherence 6 months after hearing aid fitting. The trial will also include cost analyses to determine if group visits lead to cost savings over the immediate treatment period as well as through a 6-month rehabilitation period. Results from that trial are expected in early 2009.

\section{CONCLUSIONS}

This retrospective review shows that group hearing aid visits do not worsen and may improve short-term hearing aid outcomes when compared with individual visits. If these visits result in lower costs, they could provide a means for reducing the strain on VA resources and waiting times while maintaining or improving care for more veterans. Results from a randomized controlled trial currently under way will provide more definitive answers about the long-term effectiveness of group visits in terms of hearing aid patient outcomes and costs.

\section{ACKNOWLEDGMENTS}

This material was unfunded at the time of manuscript preparation. The views expressed in this article are those of the authors and do not necessarily represent the views of the VA.

\footnotetext{
*National Institutes of Health ClinicalTrials.gov. Available from $<$ http://www.clinicaltrials.gov/ct/gui >
} 
JRRD, Volume 44, Number 5, 2007

The authors have declared that no competing interests exist.

\section{REFERENCES}

1. Veterans Benefits Administration. Veterans Benefits Administration annual benefits report fiscal year 2005. Washington (DC): U.S. Department of Veterans Affairs; 2005.

2. Dunlop RJ, Beck LB, Dennis KC, Gonzenbach SA, Abrams HB, Berardino JT, Styer SA, Hall A. Support personnel in VA audiology. Audiol Today. 2006;18(1):24-25.

3. VHA Forms, Publications \& Records Management [homepage on the Internet]. Washington (DC): U.S. Department of Veterans Affairs [updated February 2007]. Directive 2006.028; [2 screens]. Available from: http://www1.va.gov/vhapublications/

4. Hearing Loss Association of America [homepage on the Internet]. Bethesda (MD): The Association; c2005-6 [updated 2007 Feb 12; cited 2004 May 11]. Position on group hearing aid orientation programs; [1 screen]. Available from: http://www.hearingloss.org/html/group hearing aid orientation .HTM

5. Abrams HB, Hnath-Chisolm T, Guerreiro SM, Ritterman SI. The effects of intervention strategy on self-perception of hearing handicap. Ear Hear. 1992;13(5):371-77. [PMID: 1487096]

6. Abrams HB, Chisolm TH, McArdle R. A cost-utility analysis of adult group audiologic rehabilitation: Are the benefits worth the cost? J Rehabil Res Dev. 2002;39(5):549-58.

7. Andersson G, Melin L, Scott B, Lindberg P. An evaluation of a behavioural treatment approach to hearing impairment. Behav Res Ther. 1995;33(3):283-92. [PMID: 7726804$]$

8. Andersson G, Melin L, Scott B, Lindberg P. A two-year follow-up examination of a behavioural treatment approach to hearing tactics. Br J Audiol. 1995;29(6):347-54. [PMID: 8861410$]$

9. Beynon GJ, Thornton FL, Poole C. A randomized, controlled trial of the efficacy of a communication course for first time hearing aid users. Br J Audiol. 1997;31(5):345-51. [PMID: 9373743]

10. Chisolm TH, Abrams HB, McArdle R. Short- and longterm outcomes of adult audiological rehabilitation. Ear Hear. 2004;25(5):464-77. [PMID: 15599193]

11. Hallberg LR, Barrenas ML. Group rehabilitation of middle-aged males with noise-induced hearing loss and their spouses: evaluation of short- and long-term effects. $\mathrm{Br} \mathrm{J}$ Audiol. 1994;28(2):71-79. [PMID: 7841891]

12. Hawkins DB. Effectiveness of counseling-based adult group aural rehabilitation programs: a systematic review of the evidence. J Am Acad Audiol. 2005;16(7):485-93. [PMID: 16295235]

13. Hickson L, Worrall L. Beyond hearing aid fitting: Improving communication for older adults. Int J Audiol. 2003; 42(Suppl 2):2S84-91. [PMID: 12918634]

14. Norman M, George CR, Downie A, Milligan J. Evaluation of a communication course for new hearing aid users. Scand Audiol. 1995;24(1):63-69. [PMID: 7761802]

15. Northern JL, Beyer CM. Reducing hearing aid returns through patient education. Audiol Today. 1999;11(2):10-11.

16. Lesner SA, Thomas-Frank S, Klinger MS. Assessment of the effectiveness of an adult audiologic rehabilitation program using a knowledge-based test and a measure of hearing aid satisfaction. J Acad Rehabil Audiol. 2001;34:29-40.

17. Preminger JE. Should significant others be encouraged to join adult group audiologic rehabilitation classes? J Am Acad Audiol. 2003;14(10):545-55. [PMID: 14748551]

18. Smaldino SE, Smaldino JJ. The influence of aural rehabilitation and cognitive style disclosure on the perception of hearing handicap. J Acad Rehabil Audiol. 1988;21:57-64.

19. Taylor KS, Jurma WE. Study suggests that group rehabilitation increases benefit of hearing aid fittings. Hear J. 1999;52(9):48-54.

20. Brickley GJ, Cleaver VC, Bailey S. An evaluation of a group follow-up scheme for new NHS hearing aid users. $\mathrm{Br}$ J Audiol. 1996;30(5):307-12. [PMID: 8922695]

21. Koop CE. Getting the most out of your hearing aids [video]. Grand Rapids (MN): DCR Communications, Inc; 1994.

22. Ventry IM, Weinstein BE. The Hearing Handicap Inventory for the Elderly: a new tool. Ear Hear. 1982;3(3):128-34. [PMID: 7095321]

23. Weinstein BE, Spitzer JB, Ventry IM. Test-retest reliability of the Hearing Handicap Inventory for the Elderly. Ear Hear. 1986;7(5):295-99. [PMID: 3770324]

24. Yueh B, McDowell JA, Collins M, Souza PE, Loovis CF, Deyo RA. Development and validation of the effectiveness of [corrected] auditory rehabilitation scale. Arch Otolaryngol Head Neck Surg. 2005;131(10):851-56. [PMID: 16230585] Erratum in: Arch Otolaryngol Head Neck Surg. 2006; 132(1):16.

25. Cox RM, Alexander GC. Measuring Satisfaction with Amplification in Daily Life: the SADL scale. Ear Hear. 1999;20(4):306-20. [PMID: 10466567]

26. Cox RM, Alexander GC. Validation of the SADL questionnaire. Ear Hear. 2001;22(2):151-60. [PMID: 11324844]

27. Beck A, Scott J, Williams P, Robertson B, Jackson D, Gade G, Cowan P. A randomized trial of group outpatient visits for chronically ill older HMO members: the Cooperative Health Care Clinic. J Am Geriatr Soc. 1997;45(5): 543-49. [PMID: 9158573]

28. Masley S, Phillips S, Copeland JR. Group office visits change dietary habits of patients with coronary artery 
disease - the dietary intervention and evaluation trial (D.I.E.T.). J Fam Pract. 2001;50(3):235-39.

[PMID: 11252212]

29. Scott JC, Conner DA, Venohr I, Gade G, McKenzie M, Kramer AM, Bryant L, Beck A. Effectiveness of a group outpatient visit model for chronically ill older health maintenance organization members: A 2-year randomized trial of the cooperative health care clinic. J Am Geriatr Soc. 2004;52(9):1463-70. [PMID: 15341547]

30. Coleman EA, Eilertsen TB, Kramer AM, Magid DJ, Beck A, Conner D. Reducing emergency visits in older adults with chronic illness. A randomized, controlled trial of group visits. Eff Clin Pract. 2001;4(2):49-57. [PMID: 11329985]

31. Sadur CN, Moline N, Costa M, Michalik D, Mendlowitz D, Roller S, Watson R, Swain BE, Selby JV, Javorski WC. Diabetes management in a health maintenance organization. Efficacy of care management using cluster visits. Diabetes Care. 1999;22(12):2011-17. [PMID: 10587835]

32. Coleman EA, Grothaus LC, Sandhu N, Wagner EH. Chronic care clinics: A randomized controlled trial of a new model of primary care for frail older adults. J Am Geriatr Soc. 1999;47(7):775-83. [PMID: 10404919]

33. Wagner EH, Grothaus LC, Sandhu N, Galvin MS, McGregor M, Artz K, Coleman EA. Chronic care clinics for diabetes in primary care. Diabetes Care. 2001;24(4):695-700. [PMID: 11315833]

34. Ickovics JR, Kershaw TS, Westdahl C, Rising SS, Klima C, Reynolds H, Magriples U. Group prenatal care and preterm birth weight: Results from a matched cohort study at public clinics. Obstretr Gynecol. 2003;102(5 Part 1):1051-57. [PMID: 14672486]

35. Mazzuca SA, Moorman NH, Wheeler ML, Norton JA, Fineberg NS, Vinicor F, Cohen SJ, Clark CM. The diabetes education study: A controlled trial of the effects of diabetes patient education. Diabetes Care. 1986;9(1):1-10. [PMID: 3948638]

36. Raz I, Soskolne V, Stein P. Influence of small-group education sessions on glucose homeostasis in NIDDM. Diabetes Care. 1988;11(1):67-71. [PMID: 3338379]

37. Rickheim PL, Weaver TW, Flader JL, Kendall DM. Assessment of group versus individual diabetes education: A randomized study. Diabetes Care. 2002;25(2):269-74. [PMID: 11815494]
38. Trento M, Passera P, Tomalino M, Bajardi M, Pomero F, Allione A, Vaccari P, Molinatti GM, Porta M. Group visits improve metabolic control in type 2 diabetes: A 2-year follow-up. Diabetes Care. 2001;24(6):995-1000.

[PMID: 11375359]

39. Clancy DE, Cope DW, Magruder KM, Huang P, Wolfman TE. Evaluating concordance to American Diabetes Association standards of care for type 2 diabetes through group visits in an uninsured or inadequately insured patient population. Diabetes Care. 2003;26(7):2032-36.

[PMID: 12832308]

40. Hulley SB, Cummings SR, Browner WS, Grady D, Newman TB. Designing clinical research. An epidemiologic approach. 3rd ed. Philadelphia (PA): Lippincott Williams \& Wilkins; 2006.

41. Audiology Online [homepage on the Internet]. San Antonio (TX): The Association; c2007 [updated 2003 Oct 13; cited 2006 Apr]. Taylor KS. Effects of group composition in audiologic rehabilitation programs for hearing impaired elderly; [1 screen]. Available from: http://www.audiologyonline.com/articles/article detail.asp?article id=498

42. Abrahamson JE. Patient education and peer interaction facilitate hearing aid adjustment. Hear Rev. 1997;1 Suppl:19-22.

43. Abrahamson J. Group audiologic rehabilitation. Sem Hear. 2000;21(3):227-34.

44. Warner-Czyz AD. Clinical application of adult audiologic rehabilitation programs. Sem Hear. 2000;21(3):235-44.

45. Miller D, Zantop V, Hammer H, Faust S, Grumbach K. Group medical visits for low-income women with chronic disease: A feasibility study. J Womens Health (Larchmt). 2004;13(2):217-25. [PMID: 15072736]

46. Scott J, Gade G, McKenzie M, Venohr I. Cooperative health care clinics: A group approach to individual care. Geriatrics. 1998;53(5):68-70,76-78,81. [PMID: 9597981]

47. Terry K. Should doctors see patients in group sessions? Med Econ. 1997;74(1):70,75,79-82. [PMID: 10164336]

48. Hull RH. Fourteen principles for providing effective aural rehabilitation. Hear J. 2005;58(2):28-30.

49. Noffsinger EB, Scott JC. Understanding today's group visit models. Group Pract J. 2000;49(2):46-58.

Submitted for publication February 6, 2007. Accepted in revised form June 13, 2007. 